\title{
Pragmatic oriented data interoperability for smart healthcare information systems
}

Conference or Workshop Item

Accepted Version

Liu, S., Li, V. and Liu, K. (2014) Pragmatic oriented data interoperability for smart healthcare information systems. In:

The 14th IEEE/ACM International Symposium on Cluster, Cloud and Grid Computing, 26 - 29 May 2014, Chicago, USA. Available at http://centaur.reading.ac.uk/36686/

It is advisable to refer to the publisher's version if you intend to cite from the work. See Guidance on citing.

All outputs in CentAUR are protected by Intellectual Property Rights law, including copyright law. Copyright and IPR is retained by the creators or other copyright holders. Terms and conditions for use of this material are defined in the End User Agreement. 


\section{CentAUR}

Central Archive at the University of Reading

Reading's research outputs online 


\title{
Pragmatic Oriented Data Interoperability for Smart Healthcare Information Systems
}

\author{
Shixiong Liu ${ }^{1}$, Weizi $\mathrm{Li}^{1}$, Kecheng Liu ${ }^{1,2}$ \\ ${ }^{1}$ Informatics Research Centre, University of Reading, Reading, UK \\ ${ }^{2}$ School of Information Management and Engineering, Shanghai University of Finance and Economics, Shanghai, China \\ Shixiong.liu@pgr.reading.ac.uk, weizi.li@henley.ac.uk, k.liu@henley.ac.uk
}

\begin{abstract}
Smart healthcare is a complex domain for systems integration due to human and technical factors and heterogeneous data sources involved. As a part of smart city, it is such a complex area where clinical functions require smartness of multi-systems collaborations for effective communications among departments, and radiology is one of the areas highly relies on intelligent information integration and communication. Therefore, it faces many challenges regarding integration and its interoperability such as information collision, heterogeneous data sources, policy obstacles, and procedure mismanagement. The purpose of this study is to conduct an analysis of data, semantic, and pragmatic interoperability of systems integration in radiology department, and to develop a pragmatic interoperability framework for guiding the integration. We select an on-going project at a local hospital for undertaking our case study. The project is to achieve data sharing and interoperability among Radiology Information Systems (RIS), Electronic Patient Record (EPR), and Picture Archiving and Communication Systems (PACS). Qualitative data collection and analysis methods are used. The data sources consisted of documentation including publications and internal working papers, one year of non-participant observations and 37 interviews with radiologists, clinicians, directors of IT services, referring clinicians, radiographers, receptionists and secretary. We identified four primary phases of data analysis process for the case study: requirements and barriers identification, integration approach, interoperability measurements, and knowledge foundations. Each phase is discussed and supported by qualitative data. Through the analysis we also develop a pragmatic interoperability framework that summaries the empirical findings and proposes recommendations for guiding the integration in the radiology context.
\end{abstract}

Keywords-Data Interoperability; Semantic Interoperability; Pragmatic Interoperability; Semiotic Interoperability; Radiology; Heterogeneous data sources

\section{INTRODUCTION}

Smart healthcare is a complex domain for systems integration due to human and technical factors and heterogeneous data sources involved. As a part of smart city, it is such a complex area where clinical functions require smartness of multi-systems collaborations for effective communications among departments, and radiology is one of the areas highly relies on intelligent information integration and communication. Information systems integration is one of the key aspects of modern healthcare information systems. In order to achieve higher interoperability, increasing use of integration approaches and interoperability measurements significantly facilitates the collaboration across healthcare information systems. However, a large number of integration projects in healthcare end up as a failure because of the complexity of the domain due to human and technical factors and multi-stakeholder involved, and multidisciplinary nature of the problems. The radiology department in hospital is one of the typical areas that requires multi systems collaborations, and highly relies on effective communications among departments. Thus it faces many challenges regarding integration and its interoperability. For example, Information communication is challenged because the clinicians and the radiologist were located in different rooms, thereby collaboration takes place asynchronously at most of the time. Another reason caused this situation is the varieties of purchased systems for hospital. The information systems were provided by various venders, who remained their competitiveness by selling only one type of systems or focusing on one specific function. This result in that the stakeholders get frustrated more often because the communication of patient's data/information failed among various information systems. The radiology department also has several policy obstacles because the integration cuts across political boundaries causing changes (e.g. internal control process, work flow, staff relationships, communication patterns) in organisations [14]. Other barriers such as internal and external pressures, IT sophistication, and patient satisfaction have also brought much research attentions towards information systems integration in radiology department.

In the study of the interoperability, most of the works focus on discussion at a technical level and data level. Although some of them have extended to deal with semantics, a very limited number of publications elaborate the interoperability at the pragmatic level [21]. Undoubtedly the research on data and semantic interoperability can help establish a better understanding of data exchange and data interpretation, as well as leading to the development of supporting technologies and standards. However, the healthcare delivery requires pragmatic interoperability that ensures supported process can act upon the semantic information in order to deal with the complexity in healthcare environment [13]. Our past work [17] has established an intensive understanding on data and semantic interoperability. Thus this paper mainly focuses on pragmatic interoperability, and choose radiology department for case study to develop a pragmatic interoperability framework for guiding the integration. Section 2 introduces background of our previous research and the related work. Section 3 explains the 
research approach for the case study on how do we conduct the data collection and analysis. Section 4 represents the results of the pragmatic interoperability analysis including requirements of pragmatic interoperability, approaches for pragmatic integration, measurements of pragmatic interoperability, and knowledge foundations. This section also develops a pragmatic interoperability framework that summaries the empirical findings and makes recommendations for guiding the integration in the following stages of the project. Section 5 ends with conclusion and discussion of future work.

\section{BACKGROUND}

\section{A. Data and Semantic Interoperability}

In semiotic interoperability framework [17], we define data interoperability as syntactic interoperability, which is the ability to supporting data exchange between systems through compatible formats and structures. Our past study also identified barriers of data interoperability in the context of radiology:

- Data Representation Inconsistency: Contains various data representation methods such as ASCII, EBCDIC, and XML etc.

- Data Structure Heterogeneity: Same data will be described in different structures by different systems because of various application systems, DBMS and operating systems

- Interoperable Data Management: Enable context federation, query decomposition and optimization, transaction management, concurrency and recovery

The semantic interoperability is defined in semiotic interoperability framework as the Ability of interpreting and converting information into equivalent meaning to allow information sharing between systems. Barriers towards integration of healthcare information systems are:

- Semantic Heterogeneity: variation of semantic meaning in information resources, which will lead to the semantic conflicts and complication for data integration

- Ontology Structure Inconsistency: different ontology structures require matching techniques for integration

- Ambiguous Terminology: Differences in the use of terms across departments

The issue identified on both data and semantic interoperability has been dealt with by a few studies. Our past survey investigated the most widely used interoperability evaluation frameworks, and found out most of them have achieved up to semantic level, but hardly discussed the pragmatic interoperability. Thus we defined the pragmatic interoperability in our semiotic interoperability framework, and developed an assessment method for measuring it [22].

\section{B. Pragmatic Interoperability}

The semiotic interoperability framework defines pragmatic interoperability as the ability to aggregating and optimizing various business processes for achieving intended purposes of different information systems. In addition to our definition of pragmatic interoperability, other researchers have contributed in pragmatic interoperability. Benson [1] defines it as coordination of work processes across different people to enabling work collaboration. Sadeghi et al. [29] state the pragmatic interoperability in healthcare is the ability among healthcare processes and various actors (i.e. healthcare providers and patients) that interact with information systems. We address systems interaction from the perspective of semiotic interoperability; pragmatic level of semiotic interoperability is concerned with the relationship between signs and the potential behaviour and intention of responsible agents. Therefore, successful communication at this level is achieved if the hearer understands the speaker's intentions, which goes beyond the semantic interpretation of the communicative act. Interoperability is achieved at this level when processes serving different purposes under different contexts by different information systems can be composed to jointly support a common intention. The emphasis is the context awareness for processes integration. The following elements can be considered in the context: information system itself, intention, purpose, theme, time, location etc. The barriers towards pragmatic integration will be identified in this study include the following:

- Data Source heterogeneity: Multiple data sources (e.g. RIS, EPR, PACS) used for supporting clinical process

- Policy and Procedures: Internal control process, workflow, staff relationships, communication patterns, cut-across political boundaries, etc.

- Restriction to Staff Behaviour: Medical staff's fear on information systems integration as restriction that might control their behaviour

- Information Collaboration: Clinicians and radiologists located in different rooms, thus communication takes place asynchronously

- Varieties of Purchased Systems: Hospital purchased systems from various venders, which cause information communication failures

- $\quad$ Privacy and Security: Sensitive information of patient to be protected by law

The investigation on the barriers is conducted via case study in radiology department. The results help articulate the pragmatic integration requirements. Our proposed pragmatic interoperability framework will provide a guideline for solving the barriers and supporting the integration.

\section{RESEARCH APPROACH}

\section{A. Context of Case Study}

The study was conducted over a one year's period at a local hospital, one of the largest general hospital foundation trusts in the UK. It has over 4,800 staff, 607 acute, 44 paediatrics and 57 maternity postnatal beds, and provides acute medical and surgical services. The on-going project is to achieve data sharing and interoperability among Radiology Information Systems (RIS), Electronic Patient Record (EPR), and Picture Archiving and Communication Systems (PACS). The 
Radiology department provides diagnostic and interventional radiology for inpatients, outpatients and general practitioner referrals. Various healthcare services such as Computed Radiography (CR), Computed Tomography (CT), X-ray, and Interventional Radiology produce a huge amount of information regarding patient's healthcare delivery and clinical process. Hence a stable integration would enable their communication with each other become more efficiently within their IT infrastructure, and also eliminate costly point-to-point connections and manual-input processes.

\section{B. Methods}

A qualitative approach including various techniques has been adopted in the study [35]. We select an on-going project at the local Hospital for undertaking our case study. During the data collection process, 37 department members participated in this study in terms of observations and interviews. The hospital positively supported our study, as they were also very interested in the challenges we identified as well as the interoperability measurements towards the integration evaluation.

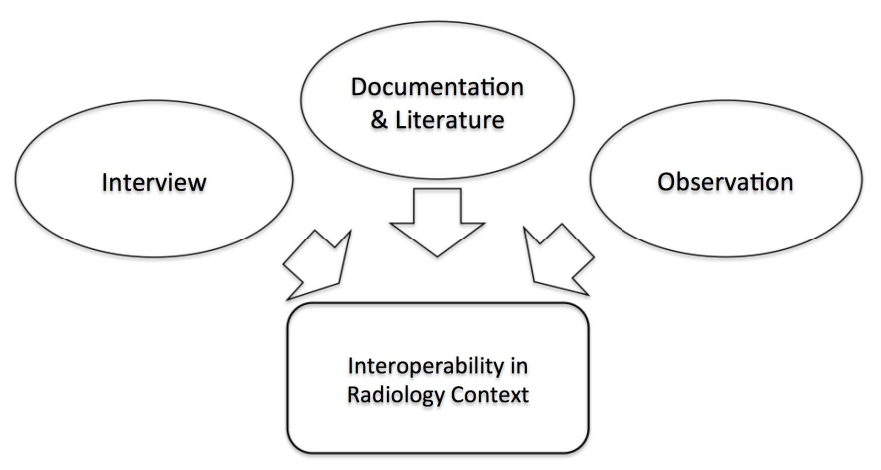

Fig. 1. Data collection methods

\section{Data Collection}

We collected data from documentation \& literature, interviews, and observations. Figure 1 depicts on how we conduct the data collections by using these three methods [6].

\section{1) Documentation \& Literature}

The documentation included literature review covering research publications, official reports, and working papers from the hospital. The research publications were sourced from several electronic databases in terms of information systems, and health informatics. The official reports were sourced from HSCIC (Health \& Social Care Information Centre), which is one of the biggest NHS supported health informatics databases. The working papers were provided by the hospital IT services department.

\section{2) Observations}

The observations at the hospital were non-participant observations. They were conducted by a trained doctoral researcher through one-year-long process of data collection. The data includes radiology work processes, staff routine, individual activities (e.g. data entry, medication order), technologies/techniques used for integration, and methods used for interoperability measurements).

\section{3) Interviews}

37 semi-structured interviews were conducted with relevant stakeholders including 9 radiologists, 12 referring clinicians, 8 radiographers, 4 directors of IT services, 3 receptionists, and 1 radiology secretary. The interviews lasted around 40 minutes and were on a one-to-one basis. The interviews were taperecorded and later transcribed and rendered anonymously.

\section{Data Analysis}

In this paper, we investigate interoperability according to information system design research paradigm. The information systems and the supported healthcare environment are complex, artificial, and purposefully designed. They require not only integrated features, but also high alignments between the healthcare processes and the system functions [8]. To accomplish this goal, healthcare information system design aids to enable the transition of healthcare process into system functions. By following this paradigm, we develop the process for data analysis (depicted in figure 2), and use it to identify the requirements and barrier, integration approach, interoperability measurement, and knowledge foundations of pragmatic interoperability from the case study.

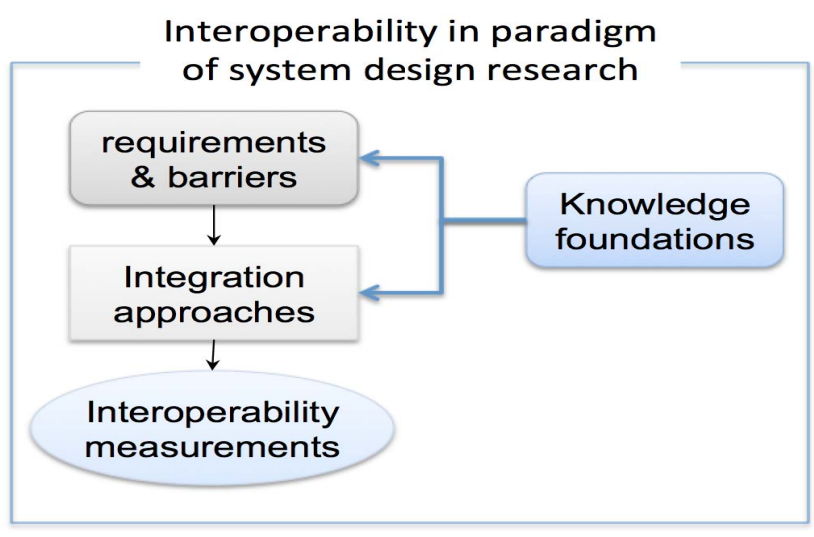

Fig. 2. Data analysis process from perspective of systems design paradigm

The requirement and barrier including obstacles, and problems are defined in environment that is composed of goals, tasks, problems, and challenges for achieving interoperability at pragmatic level. The phase of integration approach is defined as methods and techniques that improve integration of systems. The phase of knowledge foundations is defined as the knowledge repository supporting both phase of requirements \& barriers, and phase of integration approaches. It mainly covers publications that discuss interoperability in a high level without concrete development of the integration approach or interoperability measurement. The phase of interoperability measurement is defined as the methods and techniques that assess and measure the interoperability of information systems.

\section{FINDINGS ON PRAGMATIC INTEROPERABILITY IN THE CONEXT OF RADIOLOGY}

\section{A. Requirements and Barriers}

The semiotic interoperability defines the interoperability at pragmatic level as processes supported by the systems in individual contexts can be aggregated to achieve the overall 
intended purpose [17]. Foremost is the need to understand pragmatic interoperability at the process level. From our observations of case study, departments in the hospital have various clinical processes, which aim to be worked together in order to enable healthcare functions. Some researches have excavated the pragmatic issues prior to our study. For example, Gottschalk [7] concerns information quality issue when integrating clinical information sources across various quality standards. He also looks interoperability from lens of managerial. Khoumbati et al. [13] discuss constraints such as resistance of change of clinical staff, training requirement, and confidentiality of patient data. Those aforementioned are indeed key issues existing at the pragmatic level of interoperability. Therefore, we undertook several interviews during the case study to identify key requirements and barriers of pragmatic interoperability.

\section{1) Data Source Interoperability}

In the current healthcare context, patient-centred care delivery is tailored to patient and requires collaboration of several information systems (e.g. RIS, EPR, PACS). In addition, other involved team members also require the data of patient such as status and treatment. To deliver care for an individual patient, various activities need to be collaborative and to keep updating the database in real time. However, this collaboration is challenged duo to the complexity, it requires multiple data sources integrated to support the different requirements. One IT service director stated that:

"Before this integration, our IT environment operated with costly point-to-point interfaces, and we also lacked control of troubleshooting while the messages transmission failed... we operated within a manual environment where we needed to manually enter orders with their DICOM (Digital Imaging and Communications in Medicine) images received from outside reading facilities into our RIS (Radiology Information System), and had to fax copies back to the outside facility's RIS."

\section{2) Policy and Procedure}

From the policy and procedure perspective, integration of information systems always faces obstacles, because it cuts across political boundaries, and causes a mount of changes (e.g. internal control process, work flow, staff relationships, communication patterns) in organisations [14]. In the healthcare, before the integration of RIS, the political issues between clinicians and radiologists have been raised for long due to the autonomous role of clinician. Comparing with the radiologists, clinicians have the right to choose and take responsibility for their treatments made, and they have direct access to the policy making. The integration of RIS will enable the information sharing between the clinicians and the radiologists, so that patient's information and treatments made by clinicians will be transparent for the radiologists. However, it is challenged as clinicians have concerns that the information they collect and the treatments they made are proprietary and thus unavailable for inclusion in the process of information sharing. The integration of RIS also solves a political issue that clinicians who are geographically separated from the hospital were having conflicts for decision making. A quote from one clinician is:
"All decisions have to be made with support of our staff... the integration has a chance to work here only if the staff can see the benefits."

\section{3) Restriction to Staff Behaviour}

In line with the issue, another barrier comes from the medical staff is that they are seeing the information systems integration as restriction that would control their behaviour. They are more interested in research than administration, and they await more benefits to patient care delivery from the information systems integration, rather than the improvements of communication with the staff. This is the decisive factor that will let them accept the integration.

\section{4) Information Collaboration}

Information communication was challenged because the clinicians and the radiologist were located in different rooms, and therefore the collaboration takes place asynchronously at most of the time. One participant in the interview stated that:

"More channels need to be provided especially for the collaborative decision making process. The decision context should be communicated so that both clinicians and radiologists are on the same page regarding the collaboration."

\section{5) Varieties of purchased systems}

Information communication was also challenged due to the varieties of purchased systems for hospital. Originally, the hospital has from four to six different information systems with very limited integration. Those information systems were provided by several small venders, who remained their competitiveness by selling only one type of systems or focusing on one specific function. This result in that the stakeholders get frustrated more often because the communication of patient's data/information failed among various information systems. As one clinician stated:

"We became accustomed to telling our patients that we cannot provide the information for them immediately because their information cannot be accessed, although we have those information in the database... I normally have to download the hard copy and then manually re-input the data for my patient."

\section{B. Integration Approaches}

The phase of integration approach is defined as the methods and techniques that improve integration of systems. In this phase, we excavated up-to-date approaches used for improving integration at pragmatic level, and critically discussed the integration approaches adopted by the radiology department.

In the study of health information systems integration, the efforts emphasise on pragmatic integration are limited. Nazir and Pinsonneault [25] propose an external electronic integration approach that facilitate pragmatic boundary spanning by providing concrete meanings of functional interests, which enable processes coupling for more agile and responsive integration. Saraf et al. [30] develop another process coupling approach that enable activities sharing in order to integrate process spanning boundaries. One similar approach has been shared by Robicheaux and Coleman [28], who proposes the operational integration approach that indicates joint actions but has quicker assistance with exception handling. EAI (Enterprise Application Integration) method 
contains a set of techniques that not just deal with data transportation, but also include processes management [11]. Besides, concerns such as legal interoperability, business procedures, and policies are also highly relative [12].

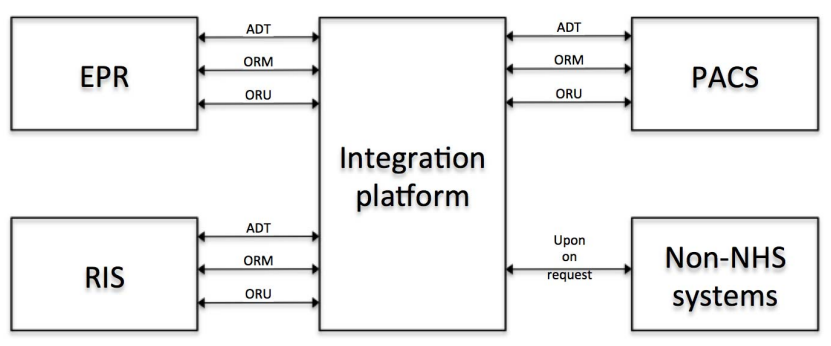

Fig. 3. Integration architecture for radiology department

Results from the case study identified the major approaches and techniques that the radiology department adopted. As the hospital consider the healthcare community as a whole, thereby its strategy aims to integrate RIS, PACS, and EPR together for supporting sharing among clinicians, radiologists, and sometimes other facilities and patients. As quoted by one director of IT services:

"We stop thinking about systems that occupy specific organizational boundaries and start to think about integrated service for the whole community."

The hospital chose EAI methodology for the integration, and used HL7 standard for exchanging documents with information systems. The integration architecture is represented in Figure below.

The whole infrastructure is delivered including several objectives: 1) to develop a central database that support information transmission between stakeholders and the data repository system; 2) to develop a web-based system for delivering applications, data, and processes; and 3) to build an integral security and navigation model for use of EPR. The objectives help to establish a best-practice approach for integration, which is a critical consideration for the better utilization of the existing information systems. The selection of integration approaches is based on the framework proposed by Themistocleous et al. [34], which evaluates the EAI integration technologies and packages. Originally, the interviewees identified selection criteria are security, process support, confidentiality, real-time integration, flexibility, and customization. After learning the framework, they reflected that the framework covers the broader categories of the criteria, and delivers the tool for integration approaches selection. They also justified their selection with several benefits of EAI approach based on the classification model developed by Shang and Seddon [32]. Those benefits can be grouped as operational, managerial, strategic, IT infrastructure, and organisational dimensions.

HL7 is selected as the standard for exchanging information with information systems. It has been widely used in healthcare environment, and represents the foundation of many healthcare information management systems. The selection of the standards is based on the evaluation framework developed by Kitsiou et al. [15], which defines seven criteria (i.e. reliability, scalability, heterogeneity, flexibility, reusability, complexity, maturity) for comparing the four major standards (i.e. HL7, CORBA, DCIOM, CEN/TC) used in information systems integration. The interviewees reflect that key characteristics such as reliability, complexity, and maturity are the critical consideration in selection. Thus they chose HL7 as it performs the most outstanding comparing with others.

\section{Interoperability Measurements}

The phase of interoperability measurement focuses on discussion of techniques for assessing interoperability. A great amount of interoperability evaluation frameworks such as LISI (Levels of Information Systems Interoperability), OIM (Operational Interoperability Model), LCM (Levels of Conceptual Interoperability Model), and EIF (European Interoperability Framework) have been developed during the past three decades. The selection of interoperability measurements is based on our developed comparative analysis of the existing interoperability measurements [21]. The NEHTA Interoperability Framework [26] has been chosen by the hospital as it defines three levels of interoperability: 1) organisation, 2) information, and 3) technical, which relates to the delivery of interoperability across health organisations (depicted in Figure 4). The organisational level is concerned with the understanding of the healthcare, regulatory, legislative and enterprise environment in which information systems need to be deployed to support healthcare delivery. The information level is concerned with representations and interpretations of clinical, administrative and statistical information. The technical level is concerned with the understanding of technical functionality for supporting information systems.

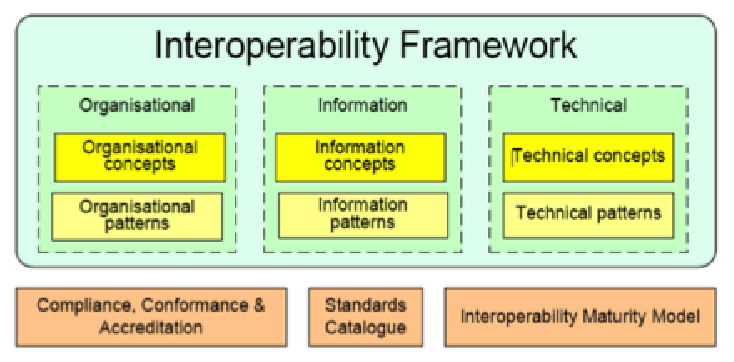

Fig. 4. NEHTA Interoperability Framework [26]

The NEHTA Interoperability Framework provides a holistic view for assessing the interoperability of the integration, but is mainly from a qualitative perspective. Apart from this, the hospital also adopts another method for quantitative measurements. The Interoperability Assessment proposed by Leite [16] develops a set of mathematical equations for addressing several issues of interoperability such as system capacity, system overload, underutilisation, and data latency. The numerical results would help provide more empirical evidences that support the integration. However, the results cannot be collected at this stage as the project is still in progress. The whole process of interoperability measurements including data from both interviews and mathematical assessment will be completed once the project is finished. 


\section{Knowledge Foundations Supporting Pragmatic Interoperability}

The phase of knowledge foundations is defined as the knowledge base supporting both phase of requirements \& barriers, and phase of integration approaches. It mainly covers publications that discuss interoperability in a high level without concrete development of the integration approach or interoperability measurement. After the analysis, we found that knowledge foundations are critically insufficient. The radiology department has not previously considered holistically viewing the integration, and they started with fixing the communication and collaboration issues instead. Hence, we made some recommendations for them to support the integration and to provide a holistically view of the interoperability. A few researchers have excavated this area, Izza [11] firstly defines four dimensions considering both vertical and horizontal integration. In the context of merge and acquisition, where information systems of two organisations tend to be integrated, Henningsson and Carlsson [9] define merger integration as a combination of organisational assets, people, process, and technology. Schweiger [31] argues that integration should start with physical consolidation of assets and functions, then move to standardisation of functions, and finally achieve coordination of functions. Mehta and Hirschheim [23] later on elaborated the level of physical coordination of functions as the part of their horizontal integration. Panian [27] classifies information systems integration into four categories: 1) data integration, 2) business process integration, 3) business activity monitoring, and 4) application integration. Euzenat [4] defines five levels of information systems integration: 1) Encoding, 2) Lexical, 3) Syntactic, 4) Semantic, and 5) Semiotic. Chen and Vernadat [2] define three levels from enterprise interoperability point of view: 1) Physical level, 2) Application level, and 3) Business level. In context of information technology and communication, Mitchell [24] classifies that integration can be concerned in three folds: 1) Data, 2) Organisation, and 3) Communication. The concept of Mitchell's classification is similar to the Open Systems Interconnection reference model (OSI) which contains seven levels: 1) Physical, 2) Data link, 3) Network, 4) Transport, 5) Session, 6) Presentation, and 7) Application (ISO/IEC, 1996).

TABLE I. PRAGMATIC INTEROPERABILITY FRAMEWORK

\begin{tabular}{|c|c|c|}
\hline $\begin{array}{l}\text { Data Analysis } \\
\text { Process }\end{array}$ & Challenges & Matters need Attentions \& Recommendations \\
\hline $\begin{array}{l}\text { Requirements } \\
\& \text { barriers }\end{array}$ & 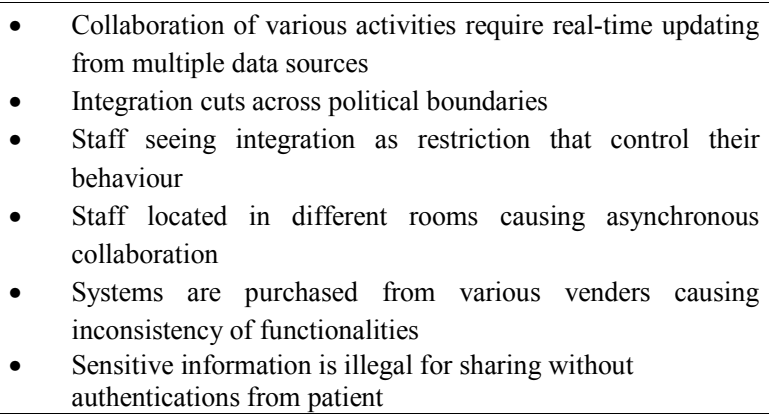 & $\begin{array}{l}\text { - Staff have fears of new technology such as the difficulties of use, } \\
\text { and causing errors } \\
\text { - Low patient satisfaction may result in repealing the integration } \\
\text { - Informal concerns such as clinician and radiologist relationships } \\
\text { may also cause obstacles for integration }\end{array}$ \\
\hline $\begin{array}{l}\text { Integration } \\
\text { approaches }\end{array}$ & $\begin{array}{l}\text { - Use EAI to enable integration at operational, managerial, } \\
\text { strategic, and IT infrastructure level } \\
\text { - Use HL7 for exchanging information with different systems } \\
\text { - } \quad \begin{array}{l}\text { Develop a web-based system for delivering processes and } \\
\text { applications }\end{array}\end{array}$ & $\begin{array}{l}\text { - } \quad \text { IHE profiles can aid to integration of clinical workflow } \\
\text { - The profiles can also address clinical information needs, and } \\
\text { establish standards as well } \\
\text { - } \quad \text { DICOM standards can specify different formats for image data } \\
\text { - } \quad \text { LOINC codes can identify medical laboratory observations }\end{array}$ \\
\hline $\begin{array}{l}\text { Interoperability } \\
\text { measurements }\end{array}$ & $\begin{array}{l}\text { - Use NEHTA Interoperability Framework to assess } \\
\text { agreements on policies and processes } \\
\text { - Use Interoperability assessment to mathematically measure } \\
\text { system utilisation, overload, and capacity }\end{array}$ & $\begin{array}{l}\text { - Semiotic interoperability framework can assess processes } \\
\text { aggregation for achieving overall intended purpose. }\end{array}$ \\
\hline $\begin{array}{l}\text { Knowledge } \\
\text { foundations }\end{array}$ & $\begin{array}{l}\text { - The radiology department has not previously considered } \\
\text { holistically viewing the integration } \\
\text { - They started with fixing the communication and } \\
\text { collaboration issues instead }\end{array}$ & $\begin{array}{l}\text { - The semiotic framework explains successful communication of } \\
\text { signs, and determines all six levels of interoperability } \\
\text { - Semiotic interoperability framework allows information systems } \\
\text { to work together through communication with insight into the } \\
\text { physical properties, transmission structure of signs, placing } \\
\text { emphasis on communicating meaning, intention and social } \\
\text { consequence of information }\end{array}$ \\
\hline
\end{tabular}

There are also some conceptual models developed for guiding evaluation of interoperability. To provide the knowledge foundations for future stages, we recommend the semiotic framework which explains successful communication of signs, and determines all six levels of interoperability, and the semiotic interoperability framework allows information systems to work together through communication with insight into the physical properties, transmission structure of signs, 
placing emphasis on communicating meaning, intention and social consequence of information.

\section{E. Pragmatic interoperability framework for systems integration at radiology department}

Through the analysis of the results from the case study, we conduct a pragmatic interoperability framework for systems integration and interoperation at the radiology department. The framework as represented in the following table that summarises the empirical findings from the case study, and proposes recommendations at each phase of our data analysis process, which will guide the integration in the next stage of the project.

In the framework, the column of current situation summarises our findings from the results of the case study. As represented the radiology department has realised the key requirements for integration, and also select EAI methodology and HL7 standard as the integration approaches for addressing those identified barriers. Based on our previous review of the existing interoperability measurements, the radiology department decides to choose the NEHTA interoperability framework for qualitative assessment, and the interoperability assessment developed by Leite [16] for quantitative assessment. Findings on the knowledge foundations appear critically insufficient, because the radiology department has not previously considered viewing the integration holistically, but fixing the collaboration issues instead. To support the department for establishing more effective integration, we propose several recommendations for each phase of the process. For example, in the phase of requirements and barriers, in addition to those identified, we also recommend to consider other resistances such as internal and external pressures, resistance to change from the staff, and patient satisfaction. Other concerns such as staff's willingness regarding the adoption of technology [18], IT sophistication, [3] and even the staff relationships are also recommended for future considerations of the integration

\section{CONCLUSION AND FUTURE WORK}

This paper conducted an analysis of pragmatic interoperability of systems integration in radiology department, and also developed a pragmatic interoperability framework in guiding the researchers to conduct systems integration in the context of radiology. We selected an on-going project at a local hospital for undertaking our case study. The project aimed to achieve data sharing and interoperability among RIS, EPR, and PACS. Qualitative data collection and analysis methods were used. We identified four primary phases of data analysis process for the case study: requirements and barriers identification, integration approach, interoperability measurements, and knowledge foundations. Each phase had been discussed and supported by qualitative data. After the analysis we recommend that the pragmatic interoperability framework should be applied to the assessment, diagnosis and implementation of systems integration. The future work will focus on data collection and analysis at the phase of interoperability measurement, and will also use the results to refine the whole analysis process and the pragmatic interoperability framework.

\section{ACKNOWLEDGEMENT}

Thanks are due to Chekfoung Tan (Informatics Research Centre, University of Reading) who helped provide materials and supporting documents.

\section{REFERENCES}

[1] Benson, T., 2009. Principles of health interoperability HL7 and SNOMED. Springer.

[2] Chen, D., Vernadat, F., 2004. Standards on enterprise integration and engineering — state of the art. Int. J. Comput. Integr. Manuf. 17, 235253.

[3] Ding, Y., 2013. Study of collaborative management of supply chain in an IT environment. J. Ind. Eng. Manag. 6, 89-99.

[4] Euzenat, J., 2001. Towards a principled approach to semantic interoperability. In: Proc. IJCAI 2001 Workshop on Ontology and Information Sharing, Seattle (WA US).

[5] Filipe, J.B.L., 2000. Normative Organisational Modelling using Intelligent Multi-Agent Systems. Ph.D Thesis, Staffordshire University.

[6] Gillham, B., 2000. Case study research methods. Continuum International Publishing Group.

[7] Gottschalk, P., 2009. Maturity levels for interoperability in digital government. Gov. Inf. Q. 26, 75-81.

[8] Henderson, J., Venkatraman, N., 1993. Strategic Alignment: Leveraging Information Techno- logy for Transforming Organizations. IBM Syst. J. 32, 15-27.

[9] Henningsson, S., Carlsson, S., 2011. The DySIIM model for managing IS integration in mergers and acquisitions. Inf. Syst. J. 21, 441-476.

[10] ISO/IEC, 1996. 7498-1. Information Technology - Open Systems Interconnection - Basic Reference Model: The Basic Model. Work Report.

[11] Izza, S., 2009. Integration of industrial information systems: From syntactic to semantic integration approaches. Int. J. Enterp. Inf. Syst. 3, $1-58$.

[12] Kalantari, M., Rajabifard, A., 2006. An interoperability toolkit for eLand administration. In: Sustainability and Land Administration Systems, Department of Geomatics, Melbourne. pp. 213-222.

[13] Khoumbati, K., Themistocleous, M., Irani, Z., 2006. Evaluating the Adoption of Enterprise Application Integration in Health-Care Organizations. J. Manag. Inf. Syst. 22, 69-108.

[14] Kim, K., Michelman, J., 1990. An examination of factors for the strategic use of information systems in the healthcare industry. MIS Q. 201-216.

[15] Kitsiou, S., Manthou, V., Vlachopoulou, M., 2006. A Framework for the evaluation of integration technology approaches in healthcare. In: Proceedings of the International Special Topic Conference on Information Technology in Biomedicine. pp. 26-28.

[16] Leite, M., 1998. Interoperability Assessment. PRC INC Arlingt. VA,

[17] Li, W., Liu, K., Liu, S., 2013. Semiotic interoperability - a critical step towards systems integration. In: The 5th International Conference on Knowledge Management and Information Sharing. Vilamoura, Portugal, pp. 508-513.

[18] Liu, H., Gao, Y., 2012. Evaluation system of the supply chain stability. J. Syst. Manag. Sci. 2, 70-78.

[19] Liu, K., 2000. Semiotics in Information Systems Engineering. Cambridge University Press, Cambridge.

[20] Liu, K., Liao, S.., Chong, S., 2002. Semiotics for Information Systems Engineering - re-use of high level artefacts. In: The 3rd International Symposium on Communication Systems Networks and Digital Signal Processing. Stafford, pp. 1-4.

[21] Liu, S., Li, W., Liu, K., Han, J., 2013. Evaluation frameworks for information systems integration: from a semiotic lens. In: The 3rd International Conference on Logistics, Informatics and Service Science. Reading, UK, pp. 559-568.

[22] Liu, S., Li, W., Liu, K., 2014. Assessing Pragmatic Interoperability of Information systems from a Semiotic Perspective. In: The $15^{\text {th }}$ 
International Conference on Informatics and Semiotics in Organisations. Shanghai, China.

[23] Mehta, M., Hirschheim, R., 2007. Strategic Alignment In Mergers And Acquisitions : Theorizing IS Integration Decision making. J. Assoc. Inf. Syst. 8, 143-174.

[24] Mitchell, J.., 1997. Manufacturing, Modelling and Integration. Present. a Meet. Comput. Dep. CETIM.

[25] Nazir, S., Pinsonneault, A., 2012. IT and Firm Agility : An Electronic Integration Perspective. J. Assoc. Inf. Syst. 13, 150-171.

[26] NEHTA, 2005. Towards an Interoperability Framework. Work Report. National E-health Transition Authority. 77-92.

[27] Panian, Z., 2006. Why enterprise system integration is inevitable? WSEAS Trans. Bus. Econ. 2006, 590-595.

[28] Robicheaux, R., Coleman, J., 1994. The structure of marketing channel relationships. J. Acad. Marketing Sci. 22(1) 38-51. J. Acad. Mark. Sci. $22,38-51$.
[29] Sadeghi, P., Benyoucef, M., Kuziemsky, C.E., 2011. A mashup based framework for multi level healthcare interoperability. Inf. Syst. Front. 14, 57-72.

[30] Saraf, N., Langdon, C.S., Gosain, S., 2007. IS Application Capabilities and Relational Value in Interfirm Partnerships. Inf. Syst. Res. 18, 320 339.

[31] Schweiger, D., 2002. M\&A integration: a framework for executives and managers. McGraw-Hill.

[32] Shang, S., Seddon, P.B., 2002. Assessing and managing the benefits of enterprise systems: the business man- ager's perspective. Inf. Syst. J. 12, 271-300.

[33] Stamper, R., 1973. Information in business and administrative systems. Batsford, London.

[34] Themistocleous, M., Irani, Z., O’keefe, R.M., 2001. ERP and application integration: exploratory survey. Bus. Process Manag. Journal, 7, 195204. 